\title{
ARQUEOLOGIA HISTÓRICA BRASILEIRA E O ESTUDO MISSIONEIRO DE 50 ANOS (1966-2016)
}

Cláudio Baptista Carle ${ }^{1 * *}$

\section{RESUMO}

O presente trabalho demonstra como a arqueologia histórica brasileira se desenvolveu em seu aspecto teórico e metodológico, tendo como foco especial os trabalhos desenvolvidos nos "Sete Povos das Missões Guarani-jesuíticas". Várias correntes de pensamento da arqueologia histórica marcaram a arqueologia missioneira brasileira sendo discorrido sobre este processo histórico da arqueologia.

PALAVRAS-CHAVE: arqueologia missioneira, arqueologia histórica, missões, jesuíticoguarani, teoria arqueológica.

\section{ABSTRACT}

This study demonstrate how the Brazilian historical archeology has developed in its theoretical and methodological aspect, with the special focus on the work done in the "Sete Povos das Missões Guarani-jesuíticas". Several of historical archeology currents of thought marked the archeology brazilian missionary being spoken about this historic process of archeology.

KEYWORDS: missionary archeology, historical archeology, missions, Jesuit-Guaraní, archaeological theory.

\section{RESUMEN}

Este estudio demuestra cómo la arqueología histórica brasileña ha desarrollado en su aspecto teórico y metodológico, con el enfoque especial sobre el trabajo realizado en los "Sete Povos das Missões Guarani-jesuíticas". Varias de las corrientes de pensamiento de la

1 Professor do Curso de Antropologia da Universidade Federal de Pelotas (UFPel). E-mail: cbcarle@gmail.com. 
arqueología histórica marcó la arqueología misionera brasileña hablamos acerca de este proceso histórico de la arqueología.

PALABRAS CLAVE: arqueología, arqueología histórica misión, misiones, jesuita-guaraní, la teoría arqueológica.

\title{
ARQUEOLOGIA HISTÓRICA BRASILEIRA: 50 ANOS ESTUDO MISSIONEIRO (1966-2016)
}

\begin{abstract}
É urgente uma tomada de posição da sociedade sul-riograndense no sentido de reivindicar respeito ao nosso patrimônio arqueológico nãorenovável, independente da vontade exclusivista de engenheiros, burocratas e políticos. (SOUZA, 1992, p. 48).
\end{abstract}

Os estudos no RS desenvolvem uma diversidade significativa na Arqueologia Histórica, criando-se um amplo leque de especialidades (SOUZA, 1992, p. 48). A Arqueologia Pré-histórica ${ }^{2}$ busca entender as culturas ${ }^{3}$ e etapas do passado ameríndio. A Arqueologia Histórica estuda os vestígios materiais dos grupos e acontecimentos históricos desde o século XVI até praticamente a atualidade. A metodologia da arqueologia histórica entra em contato com os vestígios das obras das classes sociais geralmente anônimas na História. Suas conclusões apontam na direção da democratização do conhecimento científico, fazendo conhecer os atos dos que foram "esquecidos" pela história oficial. A Arqueologia Subaquática ${ }^{4}$ implica em elevados custos para sua realização e a legislação vigente determina que só a Marinha do Brasil pode realizar este estudo. A Etnoarqueologia aborda os sítios pré-históricos e as populações indígenas conhecidas na mesma região ${ }^{5}$. A

$2 \quad$ Mais praticada no Rio Grande do Sul.

3 A ideia de tratar de culturas é um anseio muito antigo dos arqueólogos, mas segundo as definições vigentes de cultura estes estão longe de alcançá-lo, para tanto será necessário elaborar uma nova forma teórica e metodológica de abordar os sítios e objetos arqueológicos.

$4 \quad$ "Alguns ensaios já foram efetuados na Laguna dos Patos e Guaíba, em busca de embarcações afundadas no período da Revolução Farroupilha. Toda a região fluvial e lacustre do Estado poderá um dia ser avaliada do ponto de vista dessa metodologia, pela qual se encontrarão valiosas informações sobre a vida náutica e sobre o comércio que existia entre o vale do rio Jacuí e os portos do litoral brasileiro". (SOUZA, 1992, p. 47-48).

5 "O Etnoarqueólogo junta as informações arqueológicas com as obtidas nos documentos escritos, buscando entender as transformações sociais e culturais sofridas pelas sociedades indígenas coma crise trazida pela colonização europeia da América. A Etnoarqueologia traz \begin{tabular}{|l|l|l|l|l|l|l|}
\hline (C) Rev. Arqueologia Pública & Campinas, SP & v.11 & n.1 & p.107 & julho/2017 & ISSN 2237-8294
\end{tabular} 
Arqueologia em Obras de Engenharia ${ }^{6}$ (ditas muitas vezes de Salvamento ${ }^{7}$ ) ampliada fruto dos grandes empreendimentos de engenharia, tais como: barragens, hidroelétricas, estradas, aeroportos, projetos imobiliários etc. Os estudos demandam uma atividade bem mais pontual diretamente relacionada aos locais das obras, mas não menos científicas que as outras formas de arqueologia desenvolvidas. A Arqueologia Experimental que busca reproduzir as práticas tecnológicas do passado estudado, recriando instrumentos e utilizando-os nas prováveis funções para as quais foram confeccionados ${ }^{8}$ (Trigger, 1992). Estes estudos possibilitaram muitas vezes descaracterizar muitas definições impostas aos artefatos pelos pesquisadores da década de 60 no Brasil. Esta conjunção de forças marca a arqueologia histórica e com isso os estudos missioneiros.

A arqueologia histórica hoje, em boa parte dos trabalhos aqui realizados, é fruto da proposta de campo desenvolvida por Redman (1973), de Unidade Sociológica desenvolvida por Funari (1988) associadas à Arqueologia Histórica (Orser Jr., 1992), para o reconhecimento das ocupações históricas, congregadas com os modelos interpretativos do lan Hodder (1988), um pós-processualismo, subsidiando os estudos e seus simbolismos no sentido de reconstituir ${ }^{9}$ as formas de ocupação. A arqueológica platina amplia seus campos na Arqueologia Subaquática, Arqueologia Extensiva ou da Paisagem, a Arqueologia Urbana e a Arqueologia Industrial (Kern, 2000, p. 369).

importantes contribuições sociais, permitindo a afirmação dos direitos territoriais dos grupos indígenas sobreviventes no Estado." (SOUZA, 1992, p. 48).

$6 \quad$ Como bem identifica a Arqueóloga Gislene Monticelli, é também conhecida por arqueologia de contrato, arqueologia de projetos, arqueologia de resgate, entre outras.

7 "O Salvamento é somente um paliativo para o processo de destruição do patrimônio arqueológico envolvido na execução destas obras. A arqueologia enfrenta os mesmos problemas detectados pelos órgãos de preservação ambiental. $O$ imediatismo econômico surge como justificativa incontestável do progresso, minimizando os prejuízos ocasionados sobre o nosso patrimônio natural e cultural. No risco de perder completamente os vestígios, os arqueólogos se subordinam a trabalhar junto aos canteiros de obras, acuados pelo ronco das máquinas prestes a efetuar o estrago." (SOUZA, 1992, p. 48).

8 "A Arqueologia Experimental tem trazido importantes contribuições para a sociedade atual, informando sobre processos técnicos de bom nível no aproveitamento dos recursos disponíveis em nosso ambiente natural." (SOUZA, 1992, p. 49).

9 Reconstituir não é a melhor palavra para descrever o ato de interpretar da arqueologia atual, pode se entender este ato como a relação possível do nosso contexto atual em relação ao contexto de época expresso no registro arqueológico. 
A arqueologia no Brasil, cabe lembrar, é ligada a D. Pedro II como antropologia (PROUS; 1992, p. 7), colocando coleções africanas e europeias no Museu Nacional. Na República, os Museus Emílio Goeldi (Pará), Museu Paulista (SP) e Museu Nacional (RJ) empreenderam buscas de artefatos em sítios arqueológicos nacionais, principalmente os Sambaquis ${ }^{10}$ litorâneos do norte a sul do Brasil. Coletas de Roquete Pinto, Karl von den Steinen, K. Rath, Padberg-Drenkpohl, Bastos d'Ávila, Curt Nimuendaju, Angione Costa ${ }^{11}$, entre outros, enriqueceram os museus entre 1870 e 1950.

Após isso, surge o Decreto Lei 25, de 30 de novembro de 1937, no qual, em seu artigo primeiro, declarava:

Constitui o patrimônio histórico e artístico nacional o conjunto dos bens móveis e imóveis existentes no País e cuja conservação seja de interesse público, quer por sua vinculação a fatos memoráveis da história do Brasil, quer por seu valor arqueológico, ou etnográfico, bibliográfico ou artístico. (grifo meu).

Os bens deveriam ser inscritos em um Livro Tombo ${ }^{12}$, para proteção. Cria-se uma série de limitações à destruição dos sítios e possibilita-se sua pesquisa. O Tombo impede a destruição, demolição ou mutilação do bem ${ }^{13}$. São Miguel foi tombada e várias escavações arquitetônicas realizaram-se na área. Lucio Costa (MORAES, 2012, p. 1005) descreve então os achados de objetos escultóricos do povoado.

A arqueologia, internacionalmente discutida desde a década de 20, gera, em 1931, em Atenas, pela Sociedade das Nações, os primeiros princípios internacionais em relação ao patrimônio. Proposta a "técnica e a conservação de uma escavação impõe a colaboração estreita do arqueólogo e do arquiteto" (IPHAN, 1995, p. 17). O Estado Novo, no Brasil, marca a preocupação com o patrimônio arqueológico.

A partir de 1950, o trabalho em arqueologia passa a ser realizado com maior profissionalismo, buscando o uso de técnicas documentais mais aprimoradas e precisas,

10 Montes de conchas e restos de fauna marinha, lagunar e fluvial acumulados pelo homem no passado.

11 Primeiro manual brasileiro de arqueologia - 1934.

12 No caso dos bens arqueológicos, o Primeiro Livro Tombo, conforme artigo 4ํㅡㄹ do Decreto Lei 25.

13

Art. 17, Decreto Lei 25. 
mas ainda realizadas por amadores. Destacam-se: Guilherme Tiburtius (SC), Padre Rambo (RS), Zumblick e Ficker (SC), Rubinger (MG), Pereira Jr. e Sales da Cunha (RJ).

Firmados convênios com instituições estrangeiras levaram a projetos com universidades e instituições nacionais de pesquisa, principalmente pré-histórica. Entre estes estrangeiros, destaco: Joseph Empaire e Annette Laming (França), Paul Rivet (França), Wesley Hurt (USA), Calderón (Espanha), Peter Hilbert (Alemanha) e Clifford Evans e Betty Meggers (USA).

Em 1956, na Conferência Geral da Organização das Nações Unidas para a Educação, a Ciência e a Cultura (UNESCO), é elaborada a Carta de Nova Deli idem, p. 8193), tratando diretamente da questão arqueológica, sendo o Estado o interessado nas descobertas arqueológicas de cada país, apoiando o estudo, preservação e coleta dos vestígios. Definida a arqueologia, recomendava-se ao Estado-membro submeter a pesquisa e exploração arqueológica ao controle com autorização prévia de órgão competente, a declaração de novas descobertas a este órgão, as sanções aos infratores, ao confisco de objetos não declarados, a indicação de regime jurídico sobre o solo arqueológico, a criar critérios de proteção legal. Recomendava-se também a formação de órgãos de pesquisa arqueológica, a constituição de coleções centrais e regionais, ações educativas, a criação de regimes de pesquisa e colaboração internacional, regulamentação do comércio de antiguidades, repressão a pesquisas clandestinas e acordos bilaterais.

A UNESCO fez sentir no Brasil a necessidade de contato com pesquisadores estrangeiros para organização do patrimônio arqueológico nacional. A presença estrangeira cria a necessidade de uma regulamentação para evitar o escoamento do material. A proteção e pesquisa dos sítios arqueológicos nacionais, com foco nos sambaquis, surge com a publicação da Lei 3.924, de 26 de julho de 1961, durante o governo de João Goulart. A legislação enfática na preservação torna evidente a precariedade do conhecimento sobre sítios arqueológicos no Brasil e cria a necessidade de formação de profissionais na área de arqueologia.

Os amadores no Brasil deveriam identificar os episódios de mudança das diversas culturas aqui assentadas e determinar as origens destas, e isto deveria estar expresso na produção material de tais. Não identificamos até o momento trabalhos de cunho arqueológico que inferissem uma origem europeia ou mesmo africana para os sítios, visto estes não serem considerados de grande valor para estes amadores que estavam muito mais preocupados em estudar os vestígios de um "neolítico" e de altas culturas no Brasil. 
A dinâmica renovação da ciência (TRIGGER, 1992, p. 150) desenvolvida por Gustav Mortelius (1843-1921) aproxima formas de classificação para um amplo número de coleções por ele estudadas, elegendo variações de forma e decoração, melhorando as formas de seriação, e é posteriormente muito utilizada pelos difusionistas no Brasil. Em 1866, Olof Rygh indica que pontas de flechas e lanças encontradas em seu país eram produtos de uma "cultura y de un pueblo" e existiria (1871) "dos culturas de la Edad de la Piedra y dos pueblos de la Edad de la Piedra" (Meinander, 1981, p. 106 apud TRIGGER, 1992 , p. 157). Conceito chave utilizado até hoje, determinava que uma sociedade obedecia a padrões definidos e identificáveis, associada aos artefatos e muitas vezes aos níveis de estratificação diferente de um sítio.

A cultura que é largamente aplicada nas ciências sociais, e claramente aos artefatos arqueológicos, consiste em visíveis separações culturais através de métodos classificatórios/comparativos. Estes estudos valorizam culturas e dividem os vestígios arqueológicos por raças e identificam os povos culturalmente criativos em contraposição aos povos passivos (TRIGGER, 1992, p. 159-160). Na Europa, Gustaf Kossina (1858-1931) dedicado ao estudo das "tribus" formadoras da "raça germânica", "indo-europeia", busca comprovar a superioridade racial alemã, e a dispersão reduziu suas capacidades criativas. As publicações científicas deste período têm por característica o caráter descritivo e classificatório, sem discutir ou aprofundar teorias. Os pesquisadores da década de 1960 e 1970 caracterizavam os projetos de área em levantamentos sistemáticos de sítios, mas não o estudo de problemas específicos ${ }^{14}$. O pensamento arqueológico estava fundamentado na ideia de que as culturas tinham um polo inicial de origem e deste polo é que se desenvolviam para o resto mundo (TRIGGER, 1992, p. 145). Única área de origem, associavam sítios nacionais ao Velho Mundo onde estaria a origem mais remota do "sapiens sapiens". Origem comum com dispersão por emigração ou por difusão, criando blocos ou áreas culturais similares e adjacentes. Franz Boas (1858-1942) segue o modelo e introduz as ideias do etnólogo e geógrafo Fredrich Ratzel (1844-1901), nas quais as mais simples invenções teriam uma única origem e depois ocorreriam as difusões, que possibilitavam, então, alterações regionais conforme sua dispersão a partir do centro de origem.

14 Segundo Schmitz,1992, citado por BARRETO, Cristiana. A construção de um passado précolonial: uma breve história da arqueologia no Brasil. In: Revista da USP, São Paulo, n. 44, 2000. 
Clifford Evans e Betty Meggers (USA), no Programa Nacional de Pesquisas Arqueológicas (PRONAPA), 1965-1971, reúnem pesquisadores do país para elaborar um mapa arqueológico pré-histórico: José Proenza Brochado (UFRGS), Valentim Calderón (UF da Bahia), Ondemar Dias (Patrimônio Histórico e Artístico da Guanabara), Sílvia Maranca (Museu Paulista), Euríco Miller (Museu Arqueológico do RS), Nássara Nasser (UF do Rio Grande do Norte), Celso Perota (Museu de Arte e História do ES), Walter Piazza (UFSC), José Rauth (UF do Paraná), Mário Simões (Museu Emílio Goeldi) e os pesquisadores do Smithsonian Intitution supracitados. Foi a primeira grande escola teórica do país estabelecendo cronologias e considerações sobre organização de grupos pré-históricos no Brasil $^{15}$. Esta arqueologia metódica brasileira reúne os sítios históricos na Tradição Neobrasileira, destaque no RS os sítios missioneiros, inicialmente ligados à Tradição Tupiguarani, e os sítios da fase ${ }^{16}$ Monjolo.

Os sítios missioneiros relacionam arquitetos e arqueólogos, conforme as normas da Carta de Veneza ${ }^{17}$, maio de 1964, destaque aos remanescentes arqueológicos durante os processos de restauração. Os trabalhos de consolidação dos remanescentes missioneiros (Decreto Lei 25, de 1937) geram as primeiras ações de escavação. As Missões Jesuíticas do RS foram estudadas por José Proenza Brochado, na década de 60. Posteriormente, no

15 No Rio Grande do Sul, definidas as Tradições Arqueológicas e Complexos: Paleoíndio (os primeiros habitantes, de 12.000 anos atrás, caçadores e coletores especializados, relacionados à megafauna); Sambaquis (caçadores - pescadores generalizados, construtores de acúmulos conchíferos, habitantes do litoral); Umbu (caçadores - coletores generalizados, habitantes de áreas abertas); Humaitá (caçadores - coletores generalizados, habitantes de áreas de matas); Vieira (caçadores - coletores com horticultura incipiente, construtores de cerritos, habitantes de áreas circundantes às lagoas dos Patos e Mirim); Casa de Pedra (horticultores do planalto); Taquara (caçadores - coletores com horticultura incipiente, construtores de casas subterrâneas, habitantes do planalto); Itararé (horticultores incipientes do litoral) e Tupiguarani (horticultores ocupantes das terras férteis junto aos principais rios do Estado).

16 Fase arqueológica. Corresponde a uma divisão regional e cronológica de uma Tradição Arqueológica; por Tradição arqueológica entende-se um agrupamento de sítios cuja tecnologia de confecção de artefatos e o sistema deposicional dos mesmos é reconhecidamente desenvolvida pelos mesmos aspectos e características. A Tradição Arqueológica refere-se a técnicas e não especificamente a grupos humanos culturalmente relacionados. Fase: qualquer complexo (complexo: 'conjunto de elementos culturais entre si') de cerâmica, líticos, padrões de habitação etc., relacionados no tempo ou no espaço, em um ou mais sítios. Sendo aspectos locais de uma Tradição ou Subtradição cultural (PROUS, 1992, p. 111).

17 KERN, Arno. A Carta Internacional da Arqueologia e os Critérios Básicos para a Intervenção em Sítios Arqueológicos. In: SAB, 1996, p. 21. 
final da década de 70, o arqueólogo Fernando La Sálvia fez escavações no sítio de São Nicolau, sendo uma das maiores em arqueologia histórica no Brasil.

$\mathrm{Na}$ década de 80, em convênio com o IPHAN, os arqueólogos Arno Kern e posteriormente Pedro Mentz Ribeiro foram acompanhados por arquitetos, e muitas atividades de consolidação arquitetônica nas missões foram acompanhadas por estes arqueólogos. Este trabalho integrado propiciou um dos primeiros processos de aprendizado na relação arquitetos e arqueólogos na consolidação de remanescentes. Esta escola formou uma série de arqueólogos que passaram a trabalhar com esta temática no RS, tais como: José Otávio de Souza, Fernanda Tocchetto, Angela Cappelletti, André Jacobus, Beatriz Landa, Gislene Monticelli, Junior Domicks, Mirian Cazzetta, Arthur Barcelos, entre outros.

A partir dos anos 1980, uma segunda geração de arqueólogos brasileiros, com formação acadêmica especializada no Brasil e no exterior e projetos teóricos bem definidos, revisitaram os velhos temas sob novas perspectivas (BARRETO, 2000, p. 47). "Novas abordagens, como a etnoarqueologia, e a integração de outras fontes de dados às interpretações arqueológicas, como dados históricos, linguísticos e biológicos, acompanham as tendências da arqueologia internacional" (BARRETO, 2000, p. 47).

Os novos arqueólogos formados na prática arqueológica missioneira continuaram desenvolvendo pesquisas arqueológicas históricas já imbuídos da recomendação da UNESCO em relação à necessidade de integração com outros profissionais ${ }^{18}$. A Carta de Burra (IPHAN, 1996, p. 283), de 1980, destaca o termo bem que designa "um local, uma zona, um edifício ou outra obra construída, ou um conjunto de edificações ou outras obras que possuam uma significação cultural", destaca também os conceitos de conteúdo e o entorno, significação cultural, asubstância,a conservação, a manutenção ${ }^{19}$ e ouso

18 Vide Carta de Veneza (1964), Recomendação de Paris (1964), Normas de Quito (1967), Recomendação de Paris (1968), Recomendação de São Domingos (1974), Carta de Nairobi (1976), Carta de Burra (1980) - IPHAN, 1996; KERN, Arno. A Carta Internacional da Arqueologia. In: SAB, 1996, p. 17-48.

19 Não deve ser confundido com o termo reparação. A reparação implica a restauração e a reconstrução, e assim será considerada. A preservação será a manutenção no estado da substância de um bem e a desaceleração do processo pelo qual ele se degrada. A restauração será o restabelecimento da substância de um bem em um estado anterior conhecido. A reconstrução será o restabelecimento, com o máximo de exatidão, de um estado anterior conhecido; ela se distingue pela introdução na substância existente de materiais diferentes, sejam novos ou antigos. A reconstrução não deve ser confundida, nem com a recriação, nem com a reconstituição hipotética, ambas

\begin{tabular}{|l|l|l|l|l|l|l|}
\hline (C) Rev. Arqueologia Pública & Campinas, SP & v.11 & n.1 & p.113 & julho/2017 & ISSN 2237-8294 \\
\hline
\end{tabular} 
compatívelque requerem um impacto mínimo sobre os bens. A atuação dos arquitetos e arqueólogos passa, às vezes, pela ênfase maior para a arquitetura e, às vezes, para a arqueologia. A dinâmica da pesquisa de sítios arqueológicos históricos dissemina-se pelo RS.

Eurico Theofilo Miller (MARSUL) [1967] pesquisou o sítio arqueológico (RS-S-263) "Guarda Velha", no município de Santo Antônio da Patrulha. André Luiz Jacobus, depois, identifica como o antigo registro de Viamão (1737-1808, pertencente à coroa portuguesa), estabelecido em confronto aos espaços missioneiros para roubo do gado das missões (JACOBUS, 1994).

O LEPAS-UFSM, sob a coordenação do arqueólogo Saul Milder, entre os anos de 1994 e 1997, estuda outra Guarda de São Martinho, sítio Glaucia Cecim (RS IBM 10). Neste local (1995), foram feitos cortes estratigráficos para a verificação do potencial arqueológico do sítio ${ }^{20}$. Macedo (1999) destaca que esta guarda correspondia ao domínio espanhol. Seus remanescentes encontram-se no Município de São Martinho. A região foi importante ponto de disputa entre as Coroas Ibéricas no final do século XVIII. Posteriormente, passou ao domínio português, tornando-se um posto de cobrança de impostos das tropas de gados que subiam ou desciam a serra.

A arqueóloga Lizete Dias de Oliveira estuda os caminhos das tropas (1999), realizando escavações no Registro de Santa Vitória (1771-1800?). Este registro até então não havia sido localizado. A pesquisadora destaca que, conforme Andre Jacobus: "este registro seria uma estrutura em alvenaria de aproximadamente 20 metros quadrados, junto ao Passo de Santa Vitoria ${ }^{21 ، .}$. Esta estrutura marca a passagem de gado na região sob o controle português.

Fernanda Tocchetto, em contato com este e outros conceitos, formulou um programa de pesquisas arqueológicas no município de Porto Alegre. Intervir, salvar e

excluídas do domínio regulamentado pelas presentes orientações. A adaptação será o agenciamento de um bem a uma nova destinação sem a destruição de sua significação cultural.

20 MACEDO, José Heitor. São Martinho - Da Guarda ao Povoado - um Perfil Histórico-

Arqueológico sobre a formação da vila de São Martinho - RS. Dissertação de mestrado, PUCRS,1999.

21 DIAS, L. O.; SILVA, A.; F. BENTIN, A.; MORAIS, M. Trabalhos Arqueológicos no Registro de Santa Vitória. In: Arqueologia do Brasil Meridional, (CD-ROOM), PUCRS, 2002. 
acompanhar obras em sítios históricos com bens de interesse arqueológico ${ }^{22}$. A partir de 1994, a equipe de arqueologia instalada no Museu Joaquim José felizardo, antigo Museu de Porto Alegre, integrou-se à restauração do solar da Travessa Paraíso, Mercado Público Central, Solar Lopo Gonçalves (sede do Museu) e Praça Rui Barbosa (Centro), a partir destes primeiros estudos para uma ampla ação de preservação de vestígios arqueológicos da cidade ${ }^{23}$.

Outros programas de pesquisas em nível municipal foram se desenvolvendo no RS. Santo Antônio da Patrulha, Projeto Arqueológico do Santo Antônio da Patrulha desenvolvido com André Jacobus, Projeto de Arqueologia Urbana em Alegrete, com Tais Vargas Lima. Hoje vemos que a Arqueologia Histórica vem sendo desenvolvida por diversos centros de pesquisa no Estado, tais como: URI de Erechim, a UNICRUZ de Cruz Alta, a UFSM de Santa Maria, IAP de São Leopoldo, UFRGS de Porto Alegre, UFPel de Pelotas, a FURG de Rio Grande, o CEPA-PUCRS de Porto Alegre, o MARSUL de Taquara, a FAPA de Porto Alegre, ULBRA de Canoas, Museu J. J. Felizardo de Porto Alegre, URCAMP de Alegrete, o IPHAN de São Miguel das Missões, URI Santo Ângelo etc.

As missões foram frentes de exploração e colonização das Coroas Ibéricas com o estabelecimento das reduções jesuíticas nas margens do rio Uruguai. Ocuparam ocidental e orientalmente o rio Uruguai. No lado oriental (RS) foram estabelecidos os povoados entre os rios Ibicuí, Piratini e ljuí. A primeira fase das reduções guarani-jesuíticas, no RS, entre 1626 e 1639, finda com o ataque de bandeirantes. Na margem direita do Uruguai (Argentina), por mais de 40 anos, aguardaram e retornaram os jesuítas e missioneiros para fundarem os hoje denominados Sete Povos das Missões ${ }^{24}$, no Brasil. Pertenciam aos Trinta Povos Guarani e envolviam Argentina, Brasil, Paraguai e Uruguai, entre povoados e áreas de criação de gado e produção de erva mate.

A pesquisa arqueológica na região destes Sete Povos teve início com o Programa Nacional de Pesquisas Arqueológicas (PRONAPA), em campanhas realizadas nos anos de

22 TOCCHETTO, Fernanda e CAPPELLETTI, Angela. Intervenções arqueológicas em Porto Alegre e o exemplo de dois sítios históricos na área central da cidade, RS, Brasil. In: SAB, 1996, p. 381-392.

23

(idem).

24 São Nicolau fundado em 1626; São Francisco de Borja, fundado em 1682; São Luiz Gonzaga, fundado em 1687; São Miguel Arcanjo fundado em 1632 [no Tape] e refundada em 1687; São Lourenço Mártir fundada em 1690; São João Batista fundada em 1697; São Ângelo Custódio fundada em 1707. 
1966 a 1969. A cerâmica encontrada foi classificada como fase Missões, da Tradição Neobrasileira ${ }^{25}$.

José Proenza Brochado ${ }^{26}$, Danilo Lazzarotto, e Rolf Steinmetz utilizam a metodologia desenvolvida na interação entre a Universidade do Paraná e o Smithsonian Institution, prospecções intensivas possibilitaram produzir dados de uma sequência do desenvolvimento cultural e das direções de influências, migração e difusão ${ }^{27}$. $\mathrm{Na}$ área do Vale do ljuí, foram identificados três sítios agrupados na fase Missões: São João Batista (IJ29), e São Lourenço Mártir (IJ-38), na bacia do rio ljuí, e o de São Miguel Arcanjo (IJ-3728), na bacia do Piratini. Ainda mais seis sítios arqueológicos foram trabalhados ${ }^{29}$. Cabe ressaltar que ainda não usavam, nestas investigações, a metodologia da arqueologia histórica, sendo que a forma de investigação era ligada à arqueologia pré-histórica, base das ações do Programa no Brasil. Na década de 70, os trabalhos passam a ser mais intensos. Iniciam-se os levantamentos topográficos na região missioneira, basicamente nos povoados de São Nicolau, São João, São Miguel e São Lourenço, autorizado pelo SPHAN, e são localizados mais sítios do período missioneiro, entre outros da "primeira fase ${ }^{30 "}$.

25 BROCHADO, José Proença et al. A cerâmica das Missões Orientais do Uruguai, um estudo de aculturação indígena através da mudança na cerâmica. Arqueologia da Área do Prata. In:

Simpósio de Arqueologia da área do prata e adjacências. São Leopoldo, IAP, 1969.

26 BROCHADO, José J. J. P. Dados Parciais sobre a arqueologia do vale do ljuí. In.: Programa Nacional de Pesquisas Arqueológicas: Resultados preliminares do Segundo Ano (1966-1967), N ${ }^{\circ} 2$, Publicações Avulsas $n^{\circ} 10$, Belém: Conselho Nacional de Pesquisas/ Instituto Nacional de Pesquisas da Amazônia/Museu Paraense Emílio Goeldi, 1969, p. 11-32.

27 EVANS, Clifford. Introdução. In.: Programa Nacional de Pesquisas Arqueológicas: Resultados preliminares do Primeiro Ano (1965-1966), Publicações Avulsas $n^{\circ}$ 6, Belém: Conselho Nacional de Pesquisas/ Instituto Nacional de Pesquisas da Amazônia/Museu Paraense Emílio Goeldi, 1967, p. 7-9.

28 Com base nos pressupostos do Programa, foram realizadas coletas superficiais em três áreas do Sítio São Miguel Arcanjo. O sítio foi identificado nos registros do PRONAPA pelo número RS-lj-37, o qual se referia a sua localização em relação às bacias hidrográficas. A cerâmica encontrada foi classificada, de acordo com a metodologia do PRONAPA, como fase Missões, da Tradição Neo-brasileira.

29 Esse trabalho e seus resultados podem ser conferidos desde 1969 na publicação: BROCHADO, J. J.J.P. A Cerâmica das Missões Orientais do Uruguai. Pesquisas, n. 20, São Leopoldo, IAP, 1969.

30 NETO, Miranda. A utopia possível: missões jesuíticas em Guairá, Itatim e Tape, 1609-1767,e seu suporte econômico-ecológico/Miranda Neto - Brasília: FUNAG, 2012. 
Fernando Lá Salvia, em 1983, indica que este estudo ficou restrito a uma análise cerâmica e às considerações tecnológicas, dentro das quais estabelece a fase Missões. $O$ PRONAPA que previa a localização de sítios estabelecendo os roteiros migratórios das tecnologias primitivas. O importante no trabalho foi determinar, pela primeira vez, o conteúdo cultural baseado em uma nova documentação produzida ${ }^{31}$ - a arqueológica.

Brochado e Schmitz (1976) localizaram a redução denominada São Miguel de Itaiacecó (1632-1634), no município de São Pedro do Sul ${ }^{32}$. Em um trabalho de coletas e poços testes, foi recolhida grande quantidade de cerâmica indígena guarani (Ungulada, corrugada, corrugadas unguladas, pintadas com linhas geométricas) e guarani missioneira (sup. externa e interna vermelha). Também foram encontrados fragmentos de louça europeia, contas de vidro, facas, lascas de pedras - produzidas para fabricação de instrumentos. Esta redução localizada próxima ao rio lbicuí e foi pesquisada pelo Prof. Klaus P. Hilbert, no ano de 1997. Foram evidenciadas, neste trabalho de campo, marcas de estaca de habitações.

Redução Jesuítica de Candelária (1627-1641) foi pesquisada por Schmitz ${ }^{33}$, em 1970. Segundo Neli Machado (1999), que retoma este estudo, a redução está localizada perto do atual povoado do Rolador, no município de São Luiz Gonzaga. O que restou da redução de Candelária do Caac'apamini foram extensas áreas cobertas por telhas, cerâmica e outros. O objetivo da pesquisa de Machado era de realizar um levantamento provisório e o recolhimento de materiais variados para o estudo ${ }^{34}$. Foi aberta uma trincheira em uma possível residência dos padres. "Nessa trincheira foram encontrados fragmentos de barro cozido, com impressões de ramos e taquaras, telhas, pedaços de madeira queimada, barrotes que teriam sustentado o forro ou o teto e fragmentos de cerâmica" ${ }^{35}$. Em outras

31 LA SALVIA, F. Arqueologia nas Missões e Uma perspectiva Futura. In: Anais do V Simpósio Nacional de Estudos Missioneiros. Faculdade Dom Bosco, Santa Rosa, RS,1983.

32 BROChADO, J. P. Schmitz, P.I. Petroglifos do Estilo Pisadas no Rio Grande do Sul. In: Estudos Ibero-americanos, n. 2, PUCRS, Porto Alegre,1976. No ano de 1997 foi realizado um trabalho de campo neste local, sob a coordenação do prof. Dr. Klaus K. Hilbert, coordenador do CEPA-PURS.

33 Participaram destes trabalhos de levantamentos arqueológicos os professores José Proenza Brochado, Ítala Irene Becker, Maria helena Abraão Schorr, Rolf Steinmetz e Danilo Lazzarotto.

34 MACHADO, Neli Galarce. A Redução de Nossa Senhora Da Candelária do Caa'capamini (1627-1636). Série Dissertações de Mestrado. Ed. Unijuí, ljuí,1999.

35

Esse material encontra-se sob a guarda do Museu Diretor Pestana de ljuí. 
casas fizeram alguns cortes, sendo que em algumas se encontrou escória de ferro, ladrilhos, telhas em quantidade. Segundo Machado (1999, p. 68), os pesquisadores,na década de 70, estavam interessados em descobrir em que medida o convívio por dez anos entre índios e jesuítas teria alterado a cultura material do indígena. $\mathrm{O}$ inusitado é que estas reduções não deveriam possuir telhas, segundo o Padre Sepp, protagonista da segunda fase de missões.

Foram identificados pela PUCRS, em pesquisa recente, três outros sítios na proximidade do referido assentamento da primeira fase missioneira ${ }^{36}$, que pela grande presença de material missioneiro com grande quantidade de cerâmica torneada, típica dos Sete Povos, foram relacionados com os vilarejos existentes entre os antigos Povoados de São Luiz Gonzaga e São Nicolau.

A redução de Jesus Maria (1634-1636), localizada no atual município de Candelária, foi pesquisada por Mentz Ribeiro $(1976)^{37}$, basicamente a cerâmica analisada. Subdividida em várias fases: Botucarai (pertencente à nova fase da Tradição Tupiguarani), fase reduções (transacional entre a tradição Tupiguarani e a neobrasileira). Ribeiro destaca "a utilização de torno e do forno para a confecção da cerâmica, além das formas (alguns imitando os pratos europeus e tipos de decoração antes desconhecida" ${ }^{\text {38 }}$. O autor ainda enfatiza uma questão: "Outra dúvida é se o uso de torno e do forno (em pequenos percentuais) já exigiria um especialista ou se continuava doméstica". Foram encontradas contas de vidros, cachimbos e metais (cunhas, machados, pontas cavadeiras) (RIBEIRO,1983, p. 199).

36 Os franciscanos e dominicanos foram os primeiros a empreender missões na América. Em 1534, Inácio de Loyola funda a Companhia de Jesus, vem para o Brasil em 1549, e no Peru em 1567; esta ação no Peru em Juli foi frustrada pela ação dos mitaios e encomendeiros que retiravam os índios da redução e levavam para o trabalho não permitindo seu retorno. Este conhecimento levou os jesuítas a abrirem frente junto a outros índios controlando a entrada de não-índios e reduzindo o número por povoado, assim vão surgir as reduções Guarani do Guairá - 1610 ("primeira fase") atacada pelos bandeirantes, depois Itatim e Tape - 1626 ("segunda fase") atacada pelos bandeirantes e, por último, ("terceira fase"), 1682, os trinta povos. (NETO, Miranda. A utopia possível: missões jesuíticas em Guairá, Itatim e Tape, 1609-1767, e seu suporte econômicoecológico/Miranda Neto. Brasília: FUNAG, 2012.)

37 O primeiro trabalho publicado sobre as pesquisas nesta redução pode ser conferido em: RIBEIRO, Pedro Mentz.; MARTINS, H. E.; STHEINHAUS, R; HEUSER, L; BAUMHARDT, G. A Redução de Jesus Maria, Candelária, Rio Grande do Sul - Nota Prévia. Santa Cruz do Sul: Revista do CEPA, Museu do Colégio Mauá. Antropologia 3, n. 4, 1976.

38 RIBEIRO, Pedro Mentz. O Tupiguarani no Vale do Rio Pardo. In: Anais do VII Simpósio Nacional de Estudos Missioneiros, Santa Rosa, Fac. Dom Bosco,1983 
A aldeia de São Nicolau do Rio Pardo (1757), estudada por Mentz Ribeiro (1976, 1983), foi fundada por Gomes Freire com os índios provindos das antigas reduções. Ribeiro (1983, p. 196), destaca que "em virtude de um forte processo de aculturação observada na cerâmica da aldeia de São Nicolau de Rio Pardo, colocamos dentro da Tradição Ceramista Neobrasileira e a fase denominada Pardo".

Fernando La Salvia, entre os anos de 1979 e 1981, a convite do SPHAN (hoje IPHAN), realiza o trabalho de escavação sistemática durante quatorze meses de campo, em uma área de 4.500 metros quadrados, na redução de São Nicolau (1684). Deixaram descobertos

(....) uma série de evidências e remanescentes: a planta baixa da Igreja, do Colégio, do Hospital, os sistemas de esgotos pertencentes à latrina que se situava nos fundos da Igreja, as evidências do Cabildo e das habitações que lhe eram contíguas. (...) Além do que, fixamos a extensão máxima do sítio urbano, escavando em sua periferia o jardim que a Missão possuía e uma das áreas industriais, representada por um silo e uma eira ficando por escavar um engenho e uma olaria. (LA SALVIA, 1983, p. 213).

La Salvia (1988, p. 207), referindo-se à região missioneira, destacava que um dos problemas mais sérios que temos é o de salvar o que resta dos redutos missioneiros e dar uma visão de conjunto sobre a vida dos grupos que viveram naquelas paragens. Também observava que era preciso desenvolver pesquisas nos centros agropastoris, e não somente nos centros urbanos.

Os trabalhos de arqueologia histórica, e agora sobre este viés metodológico a partir da década de 1980, serão retomados principalmente nos sítios arqueológicos prospectados na década de 60 e 70, sobretudo, nos sítios missioneiros. A partir de 1983, a UNESCO declarou as missões Patrimônio Cultural da Humanidade. O projeto "Arqueologia Histórica Missioneira" (1985-1995) sob a coordenação do prof. Dr. Arno Alvarez Kern, traz novas propostas teóricas e metodológicas e apoia-se na escola francesa de arqueologia. Durante sua vigência, formou uma nova geração de arqueólogos, com grande número de publicações (dissertações, teses, relatórios, artigos científicos e livros). A origem deste projeto é de 1987 com a "Arqueologia Histórica Missioneira: Povoados Jesuítico-Guaranis de São Miguel, São João, São Lourenço e São Nicolau, RS - Brasil" tendo a coordenação geral da $10^{\mathrm{a}} \mathrm{CR} / \mathrm{SPHAN}$ e Fundação Nacional Pró-Memória e coordenação científica dos arqueólogos Arno Alvarez Kern e Pedro Augusto Mentz Ribeiro. Nesse mesmo ano, no local 
de construção da guarita de acesso ao sítio de São Miguel (setor de casas dos índios), foi escavada uma área de 100 metros quadrados, retirando-se muito material que hoje está sob guarda do CEPA/PUCRS. Nesta escavação, foi utilizada a técnica de Mortimer Wheeler. Realizaram várias escavações em áreas amplas com metodologia francesa.

Nas últimas décadas, com o aumento de obras de desenvolvimento (estradas, hidroelétricas, gasodutos etc) a Arqueologia de contrato ${ }^{39}$ ampliou-se. Barreto (2000, p. 47) afirma que "tem gerado até o momento um certo retrocesso científico com a volta de levantamentos meramente descritivos e classificatórios como os dos anos 1960 e 1970".

Em 1988, no antigo povoado de São Miguel Arcanjo, ao norte da praça (setor de casas dos índios), foi realizado um exame pericial em terreno particular por Vera Tromer Thadeu (SPHAN - Arqueóloga) e Vladimir Fernando Stello (SPHAN - Arquiteto). Reconheceram uma sequência de blocos de pedra e seguiram suas características construtivas: fundações de uma casa de índios. Padrão este que se repetiu intensamente nos estudos posteriores, indicando que o viés arquitetônico dirige os trabalhos de campo. José Otávio Catafesto de Souza (IPHAN), em 1991, acompanhou uma intervenção arquitetônica realizada na base da frontaria da igreja e, em 1992, acompanhou a intervenção realizada nas fundações de uma parede lateral na sacristia antiga.

O Sítio Escola Internacional Das Missões (1992), coordenado pelo arqueólogo Arno Kern, escava na edificação a leste do prédio das oficinas em São Miguel. Neste trabalho foi feita uma ampla integração das Universidades com a comunidade local. A valorização do Patrimônio Missioneiro foi incentivada através de oficinas de educação patrimonial, coordenadas por Catafesto de Souza e Beatriz dos Santos Landa. Klaus Peter Kristian Hilbert realizou levantamento (survey) na área circundante ao sítio arqueológico. Identificou diversos vestígios relacionados ao povoado missioneiro. Também foram localizados sítios de horticultor Guarani e de caçadores coletores associados à Tradição Arqueológica Humaitá. Estas ações realizadas em São Miguel direcionaram as atividades depois realizadas em São Lourenço, São João e São Nicolau. A preocupação com a preservação e consolidação dos vestígios tornava-se o foco das ações. 39 Assim definida por ser realizada através de contratos feitos com arqueólogos por empresas
privadas e estatais. 
O IPHAN ${ }^{40}$ considera estas reduções como um Patrimônio Cultural comum de Argentina, Bolívia, Brasil, Paraguai e Uruguai e cuja integração política e econômica do Cone Sul tem nestas Missões o seu elo cultural. As Universidades engajaram-se e, segundo este Instituto, as comunidades locais também. Até o momento, é um engajamento das universidades que o IPHAN escolhe e a comunidade só é representada pelo poder público municipal e eventualmente com o uso de estudantes de escolas próximas, a título de apoio aos trabalhos e realização de Educação Patrimonial.

O IPHAN iniciou, quando das comemorações dos 300 Anos das Missões em 1987, um intercâmbio com as equipes técnicas da Argentina, do Paraguai e da Bolívia, buscando ações conjuntas sem a efetiva participação da população como era apregoado no projeto. $O$ aproveitamento do enorme potencial de desenvolvimento econômico das missões ${ }^{41}$ ainda é insignificante.

Em 1994, foi realizado o $1^{\circ}$ Programa integrado de valorização dos sítios arqueológicos missioneiros - Mutirão Missões (PIV). Pesquisas arqueológicas em duas áreas de São Miguel onde participaram os arqueólogos Alejandra Funes (Argentina), José Otávio Catafesto de Souza e a arquiteta Matilde Villegas numa evidente procura de dados arquitetônicos de escoamento de águas em São Lourenço. O Programa Integrado de Valorização dos Sítios Arqueológicos Missioneiros, segundo o IPHAN ${ }^{42}$, conseguiu efetivar e ampliar a participação dos órgãos oficiais locais.

Em 1995, foi realizado o 2ํ PIV com o arqueólogo Cláudio Baptista Carle. O objetivo era liberar parte do muro de contenção que existe entre a área de aprovisionamento (quinta) e o conjunto principal (cemitério, templo, colégio e oficinas), com tradagens e desentulhamentos, deixando estruturas aparentes para sua consolidação. Nesse mesmo ano foi realizado um "Laudo Ambiental e Estudos Arqueológicos Referentes à Área Destinada à Implantação do Parque Arqueológico da Fonte Missioneira, São Miguel das Missões - RS" de autoria dos engenheiros florestais Marcus Chamon Schmidt, Luis Cláudio da Silva, Paulo Fernando Machado e do arqueólogo Cláudio Baptista Carle, em que foram localizados dois sítios de caçadores pré-cerâmicos, um barreiro missioneiro, as estruturas contíguas a fonte missioneira, e outros locais com restos cerâmicos ligados à Missão. Os

\footnotetext{
$40 \quad$ Fonte: missoes.iphan.gov.br. Acesso em: agosto de 2004.

$41 \quad$ Fonte: missoes.iphan.gov.br. Acesso em: agosto de 2004.

42 (idem).
} 
materiais destes trabalhos agora passaram a ser depositados no Laboratório de Arqueologia do Museu das Missões e São Miguel.

O 3ำ Mutirão Missões (PIV), em 1996, foi coordenado por Luiz Antônio Bolcato Custódio (arquiteto), Luis Claudio da Silva (Eng. Florestal), José Otávio Catafesto de Souza (Etnoarqueólogo), Vladimir Fernando Stello e Matilde Villegas (arquitetos). O programa contou com curso de preparação dos participantes acerca da história e trajetória das ações na região das missões, oficinas e atividades programadas específicas de cada área, programação cultural e visitas orientadas, além do acompanhamento de pesquisadores e técnicos das diversas áreas e instituições. Este possibilitou trabalhos em São João Batista e São Miguel Arcanjo ${ }^{43}$.

O 4ํ PIV (1997), sob mesma coordenação, teve o curso de preparação aos participantes sendo apenas desenvolvido no Sítio Arqueológico de São Lourenço Mártir, contando com a participação de alunos da Universidade Federal de Santa Maria e com apoio da Prefeitura Municipal de São Luiz Gonzaga e do Exército Brasileiro/4ํㅡㄴ RCB. A quinta edição (1998) propiciou uma perícia em rua pública de São Miguel, área destinada à Polícia Militar, por Beatriz dos Santos Landa. O local foi escavado por José Otávio de Souza, encontrando vestígios de dois alpendres de casas e de uma esquina de rua missioneira, inviabilizando a área para a construção. Nesse ano, uma área de 30.000 metros quadrados de propriedade privada destinada à construção de um restaurante foi escavada sem serem encontrados vestígios que impedissem a edificação.

A mesma arqueóloga realizou outra investigação na área do lote $n^{\circ} 1$, quadra 29 , setor 1 da cidade, para a construção de Albergue da Juventude, evidenciando a existência de materiais superficiais e a necessidade de realizar trabalho mais detalhado na área. Neste sentido, no mesmo ano, foi realizada uma perícia na área de instalação do Albergue da Juventude, na área sudoeste do sítio, sendo encontrada parte de um ducto antigo escavado no solo. Neste trabalho também foram feitas coletas sistemáticas de material e escavações, sendo que o material está depositado no Museu das Missões. A área foi liberada para a construção do Albergue. Outro trabalho realizado, nesse ano, foi de investigação da área do clube aos fundos da Quinta da Missão, sendo apenas localizada restos de uma fundação. Esta evidência precisaria de uma escavação para confirmar se é do período missioneiro.

43 (ibidem). 
$\mathrm{Na}$ área destinada a esta Torre de Telefonia, foi feito um trabalho de levantamento arqueológico pelo arqueólogo José Alberione dos Reis, em 1999, o qual não identificou nenhuma estrutura aparente, devendo, então, ser monitorada a abertura das fundações da torre para dirimir quaisquer possibilidades de destruição de vestígios arqueológicos. A continuidade dos trabalhos foi realizada por Cláudio Carle.

No 6 PIV (2000), em um sítio escola em São Lourenço Mártir, Klaus Hilbert, com apoio de Carle, estuda área das antigas casas indígenas fora do perímetro atualmente cercado do sítio, envolveu o IPHAN e a prefeitura municipal de São Luiz Gonzaga.

Cláudio Carle e Klaus Hilbert, no 7ํ PIV (2001), em São Miguel, atuam em quatro áreas: no interior da igreja, nas bases do pórtico de entrada da igreja, na área das casas junto à praça e na área do futuro Centro de Documentação Museu das Missões (casas dos índios). O material recolhido desses dois anos anteriores foi analisado em laboratório por integrantes do CEPA-PUCRS. Um duplo trabalho de desenterramento de ossos humanos no interior da igreja e de escavação acadêmica nas outras áreas.

Hilbert retorna em 2002 à São Lourenço com o apoio da prefeitura municipal de São Luiz Gonzaga e atua nos vestígios de casas indígenas missioneiras. O material foi analisado no CEPA-PUCRS, sob a responsabilidade de Cláudio Carle. Nesse mesmo ano, foram levantadas diversas estruturas relacionadas e associadas ao período missioneiro, em cidades vizinhas, e a arqueologia visa à dinâmica geral dos povoados entendendo-os como um corpo amplo que chamavam Província.

Klaus Hilbert, Cláudio Carle e Clarissa Sanfelice Rahmeier coordenaram o Projeto de Levantamento, Salvamento e Monitoramento:Arqueologia e Valorização Patrimonial do pátio de residência em Santo Ângelo Custódio (2003), justificado pela necessidade de estudo de "impacto ambiental na instalação de empreendimento turístico na área" (CARLE, 2003, p. 8). A parceria entre o Narq-UNICRUZ e o CEPA-PUCRS realiza arqueologia em Santo Ângelo, em 2004, com oficina na VI Jornadas de História da UNICRUZ. O Projeto criou equipe de estudantes da UNICRUZ e da URI-Santo Ângelo, Carle e Rahmeier fazem um sítio escola. O material e os dados obtidos foram analisados no laboratório do Núcleo de Arqueologia - UNICRUZ. Este projeto estendeu-se até 2007 com pesquisas realizadas em áreas diferentes ligadas ao antigo povoado missioneiro de Santo Ângelo.

Carle coordena a equipe da UNICRUZ em 2005 (solicitado pela 12ª Sub-Regional da $12^{\text {a }}$ Superintendência Regional do IPHAN), em São Miguel, numa das etapas de 
reconhecimento e valorização de possíveis Unidades Arqueológicas do Antigo Povo de São Miguel. Precedia aos impactos culturais na execução de obras, a presença de pisos na área central da Igreja determinou a não intervenção arquitetônica na área.

O "Programa de Acompanhamento e Monitoramento Arqueológico das Obras de Modificações na Praça Pinheiro Machado, Sítio Arqueológico da Antiga Redução de Santo Ângelo Custódio", realizado entre 2006 e 2007, em convênio com o Núcleo de Arqueologia do $\mathrm{CCM} / \mathrm{URI}^{44}$, continua de forma permanente com um programa de vistorias arqueológicas na área do Centro Histórico. O "Programa de Vistoria, Prospecção, Resgate e Monitoramento Arqueológico de Obras no Centro Histórico de Santo Ângelo, Área do Sítio Arqueológico da Antiga Redução de Santo Ângelo Custódio", coordenado pela arqueóloga Raquel Rech, traz projetos de educação patrimonial promovidos pelo Núcleo de Arqueologia do Museu Municipal Dr. José Olavo Machado. Os trabalhos estendem-se até hoje com acompanhamentos esporádicos em áreas que sofrem interferência no solo na antiga redução de Santo Ângelo.

Os arqueólogos Tobias Moraes e Vera Thaddeu, Projeto de Proteção e Valorização do Patrimônio Cultural das Missões Jesuíticas dos Guaranis (MORAES, 2012), atuam entre 2003 e 2005, nos sítios arqueológicos de São Lourenço Mártir e São João Batista e entre 2008 e 2009, na Fonte Missioneira em São Miguel (pesquisada nos anos 90). Estruturas do abastecimento hídrico do local foram identificadas. Moraes pensa que estes projetos da alternativa à antiga proposta de Arno Kern, Arqueologia Histórica Missioneira, com uma preocupação em compor um panorama da ocupação.

O Colóquio França-Brasil sobre Patrimônio Cultural (2009) reúne o IPHAN e DAPA (Direção de Arquitetura e do Patrimônio - Ministério da Cultura e Comunicação da França), em convênio de cinco anos, regulando experiências, envolvendo a pesquisa e o intercâmbio metodológico no âmbito do patrimônio arqueológico, marítimo e fluvial, e de inventário. "O acordo também estabelece a valorização e a gestão do patrimônio industrial do século XX e a formação de especialistas franceses e brasileiros". A cooperação troca experiências, informações e faz missões técnicas de especialistas dos dois países ${ }^{45}$.

\footnotetext{
${ }_{44}$ Centro de Cultura Missioneira, Universidade Regional Integrada do Alto Uruguai e das Missões

45

Fonte: http://portal.iphan.gov.br/noticias/detalhes/2628. Acesso em: agosto de 2016.
} 


\section{Revista de Arqueologia Pública}

A constante perspectiva de ampliação e a necessidade de sistematizar os estudos arqueológicos históricos levou o arqueólogo Arno Kern a propor um programa que possibilitasse a reunião dos dados em um sistema único. Para a realização de tal, integraram-se na fase do projeto os arqueólogos Cláudia Uessler e Cláudio Carle, resultando no Grupo Internacional de Pesquisa da Região do Rio da Prata, hoje Projeto Internacional de Investigações Interdisciplinares da Região Platina Oriental (PRÓ-PRATA) que contou com diversos arqueólogos e instituições do país e do Cone Sul para formação inicial de um banco de dados digital acessível pela internet e com o objetivo de criar grupos de discussão dos resultados das pesquisas arqueológicas históricas na América do Sul, este iniciou-se em 2002 e se estendeu até 2016.

A Arqueologia Missioneira foi desenvolvida durante 50 anos, resultando em inúmeras publicações e ações de educação patrimonial que a valorizaram ainda mais. Hoje está em fase de estagnação por uma ação impeditiva do IPHAN na realização de estudos de cunho acadêmico na área dos povoados. Os arqueólogos, para superar este problema, atuam nas áreas vizinhas aos povoados ampliando o conhecimento sobre a Província Jesuítica do Paraguai. 


\section{Revista de Arqueologia Pública}

\section{REFERÊNCIAS}

BARRETO, Cristiana. A construção de um passado pré-colonial: uma breve história da arqueologia no Brasil. In: Revista da USP, São Paulo, n. 44, 2000.

BROCHADO, J. J. J. P. Histórico das pesquisas arqueológicas no Estado do Rio Grande do Sul. In: IHERINGIA, Antropologia n.1 Porto Alegre,1969a.

BROCHADO, J.J.J.P. A Cerâmica das Missões Orientais do Uruguai. Pesquisas, n. 20, São Leopoldo, IAP,1969.

BROCHADO, José J.J.P. Dados Parciais sobre a arqueologia do vale do Ijuí. In: Programa Nacional de Pesquisas Arqueológicas: Resultados preliminares do Segundo Ano (19661967), $N^{\circ} 2$, Publicações Avulsas $n^{\circ}$ 10, Belém: Conselho Nacional de Pesquisas/ Instituto Nacional de Pesquisas da Amazônia/Museu Paraense Emílio Goeldi, (p.11-32), 1969.

BROCHADO, Jose Proença et all. A cerâmica das Missões Orientais do Uruguai, um estudo de aculturação indígena através da mudança na cerâmica. Arqueologia da Área do Prata. In: Simpósio de Arqueologia da área do prata e adjacências. São Leopoldo, IAP ,1969.

BROCHADO, José et al. Arqueologia Brasileira em 1968 - Um relatório preliminar sobre o Programa Nacional de Pesquisas Arqueológicas. In: Publicações Avulsas no 12 Belém: Museu Emílio Goeldi, 1969.

BROCHADO, J. P. Schmitz, P. I. Petroglifos do Estilo Pisadas no Rio Grande do Sul. In: Estudos Ibero-americanos n.2, PUCRS, Porto Alegre,1976.

CARLE, Cláudio Baptista. Projeto de Levantamento, Salvamento e Monitoramento: Arqueologia e Valorização Patrimonial de Pátio de Residência em Santo Ângelo Custódio, RS. Cruz Alta: Unicruz, 2003.

CARLE, Cláudio Baptista \& UESSLER, Cláudia As Pesquisas em Sítio Arqueológicos Históricos no Estado do Rio Grande do Sul.Conferência apresentada no V Congresso Internacional de Estudos Ibero-Americanos, entre os dias 15 e 19 de setembro, Porto Alegre: PUCRS, 2003.

Conselho Nacional do Meio Ambiente Resoluções do CONAMA - 1984 a 1991. $4^{\mathrm{a}}$ ed. Brasília: IBAMA, 1992. 
DIAS, Adriana Schmidt. Repensando a Tradição Umbu a partir de um Estudo de Caso. Porto Alegre, Dissertação de Mestrado. IFCH-PUCRS,1994.

DIAS, L. O. SILVA, A . F. BENTIN, A. MORAIS, M. Trabalhos Arqueológicos no Registro de Santa Vitória. In: Arqueologia do Brasil Meridional, (CD-ROOM) PUCRS, 2002.

EVANS, Clifford Introdução. In: Programa Nacional de Pesquisas Arqueológicas: Resultados preliminares do Primeiro Ano (1965-1966), Publicações Avulsas nº 6, Belém: Conselho Nacional de Pesquisas/ Instituto Nacional de Pesquisas da Amazônia/Museu Paraense Emílio Goeldi, p. 7-9, 1967.

FUNARI, Pedro P. Abreu. Arqueologia. São Paulo: Editora Ática, 1988.

IPHAN. Cartas Patrimoniais - Caderno de Documentos, n 3, Brasília: IPHAN, 1995.

IPHAN - Deprom Sítio das Araras - Projeto de Sinalização. Brasília: IPHAN - Deprom, 1998.

JACOBUS, A. L. Registro de Viamão: aportes históricos e Arqueológicos. Comunicação apresentada no II Seminário Nacional sobre tropeirismo, Bom Jesus, 1994.

JACOBUS, André Luiz. Resgate Arqueológico e Histórico do Registro de Viamão (Guarda Velha, Santo Antônio da Patrulha - RS). Dissertação de Mestrado, PUCRS, Porto Alegre,1996.

KERN, Arno. A Carta Internacional da Arqueologia e os Critérios Básicos para a Intervenção em Sítios Arqueológicos.In: SAB, 1996.

KERN, Arno. Arqueologia Pré-histórica do Rio Grande do Sul. Porto Alegre: Mercado Aberto, 1991.

KERN, Arno. Temas e Problemas da Arqueologia do Rio da Prata. In: Anais do III congresso Internacional de Estudos Ibero-Americanos. EDIPUCRS, Coleção Historia, Porto Alegre, 2000.

LA SALVIA, F. Arqueologia nas Missões e Uma perspectiva Futura. In: Anais do V Simpósio Nacional de Estudos Missioneiros. Faculdade Dom Bosco, Santa Rosa, RS, 1983. 
LORÊDO, Wanda Martins. Manual de conservação em arqueologia de campo. Rio de Janeiro: IBPC - Deprot, 1994.

MACEDO, Jose Heitor. São Martinho - Da Guarda ao Povoado - um Perfil HistóricoArqueológico sobre a formação da vila de São Martinho-RS. Dissertação de mestrado, PUCRS, 1999.

MACHADO, Neli Galarce. A Redução de Nossa Senhora Da Candelária do Caa'capamini (1627-1636). Série Dissertações de Mestrado. Ed. Unijui, ljuí,1999.

MILLER, Eurico Th. Pesquisas arqueológicas efetuadas no nordeste do Rio Grande do Sul, Programa Nacional de Pesquisas Arqueológicas. Resultados preliminares do Primeiro ano. 1965-1966, Belém do Para, In: Publicações avulsas n. 6, Conselho Nacional de Pesquisas, Instituto Nacional de Pesquisas da Amazônia, Museu Paraense Emílio Goeldi: Belém do Para, 1967.

MOLINA MONTES, Augusto. Considerações sobre a restauração arquitetônica em arqueologia Brasília: IPHAN - Deprom, 1998.

MORAES, Tobias Vilhena de. Preservação arqueológica nas missões jesuítico-guaranis. In: Teixeira, André \& Bettencourt José António (Coord.). Velhos e novos mundos, estudos de arqueologia moderna. ArqueoArte, n. 1, Volume 2,Lisboa, Centro de História de Além-Mar - Faculdade de Ciências Sociais e Humanas - Universidade Nova de Lisboa - Universidade dos Açores, (p. 1005-1010), 2012.

NETO, Miranda. A utopia possível: missões jesuíticas em Guairá, Itatim e Tape, 16091767, e seu suporte econômico-ecológico. Brasília: FUNAG, 2012.

PEREZ, Alejandro Villalobos. Introduccion a la conservacion del patrimonio arquitectonico - material didactico 1999 - 1. Mexico: Univ. Nac. Aut. Do Mexico, Faculdad de Arquitectura, 1999.

PROUS, André. Arqueologia Brasileira, Brasília: Ed. Da UnB, 1992.

RECH, Raquel Machado. Arqueologia urbana no Centro Histórico de Santo Ângelo: a identificação da Redução de Santo Ângelo Custódio. In: SIMPÓSIO INTERNACIONAL IHU A Experiência Missioneira: Território, Cultura e Identidade, 12, São Leopoldo, 2010. ANAIS...São Leopoldo: Ed. UNISINOS, 2010. Disponível em: 
<http://www.unisinos.br/_diversos/simposio/experiencia/experiencia _missioneira.zip>. Acesso em: 24 mai. 2012.

RIBEIRO, Pedro Mentz. O Tupiguarani no Vale do Rio Pardo. In: Anais do VII Simpósio Nacional de Estudos Missioneiros, Santa Rosa, Fac. Dom Bosco, 1983.

RIBEIRO, Pedro Mentz.; MARTINS, H. E.; STHEINHAUS, R; HEUSER, L; BAUMHARDT, G. A Redução de Jesus Maria, Candelária, Rio Grande do Sul - Nota Previa. In: Revista do CEPA, Santa Cruz do Sul, Museu do Colégio Mauá. Antropologia 3, n. 4, 1976.

SAB. Anais VIII Reunião Científica - Sociedade de Arqueologia Brasileira. Porto Alegre: PUCRS - SAB (2 vol.), 1996.

SEPP, Antônio. Viagem as Missões Jesuíticas e Os Trabalhos Apostólicos. Belo Horizonte, Ed. Itatiaia, 1980.

SOUZA, José Otávio Catafesto de Parecer 10/92 - Núcleo de Arqueologia - 12ª CR/IBPC (atual IPHAN). Parecer informando sobre situação do Patrimônio arqueológico do Rio Grande do Sul, atendendo solicitação dos Promotores de Defesa comunitária Ministério Público do Estado. Arquivos da 12ª̄SR/IPHAN, Outubro de 1992: 07.

TOCCHETTO, Fernanda e CAPPELLETTI, Ângela. Intervenções arqueológicas em Porto Alegre e o exemplo de dois sítios históricos na área central da cidade, RS, Brasil. In: SAB, (p. 381-392), 1996.

TRIGGER, Bruce G. História do Pensamento Arqueológico. Editorial Crítica: Barcelona, 1992. 